\title{
Economic sustainability in the era of complex technological systems: a fresh approach
}

\author{
Svetlana Orekhova, and Marina Evseeva \\ Ural State University of Economic, 8 Marta Str., 62, 620144 Ekaterinburg, Russia
}

\begin{abstract}
The article presents a view on the structure and stability of the economic system through the prism of interconnected technologies. Based on the genesis of the term "technology", as well as methodological provisions of the theory of complexity and neo-institutional economic theory, the concept of "technological system" as a special mechanism for coordination is introduced. Technology is considered as a system of interspecific resources and institutions. The boundaries of technological systems are defined by a bundle of interrelated technologies that function continuously through the implementation of self-executing institutional agreements. Four distinguished types of technological systems differ in the distribution of the bundle of property rights and the level of centralization.It is shown that the introduction of the concept of "technological systems" into scientific circulation will expand the understanding of mechanisms ensuring sustainable economic growth.
\end{abstract}

\section{Introduction}

In the post-pandemic era, issues of sustainability of economic systems at all levels - from global to local - come to the fore. Sustainability is considered as the ability of a system to return to stable functioning after external influences. At the same time, according to the concept of sustainable development, the functioning of the system in the present shouldn't worsen the potential well-being of future generations.

The problem of maintaining sustainable development is aggravated by complicating economic systems. In economic practice, more and more phenomena that don't fit into either the standard classification of "markets and hierarchies" or into the "micro-macro" dichotomy arise. We see the space of institutions, network structures (blockchains, technological platforms, etc.), hybrid forms, agglomerations, etc., and the interactions between them are becoming more and more complicated [1].

Against this background, production technologies are converging, and companies can no longer develop and implement them on the basis of their own material and intellectual resources. As a result, transactions of various agents (from technology entrepreneurs to large production concerns) are expanding in a wide variety of configurations. The formation of network structures in the modern economic space changes the classical ideas about the technological boundaries of companies - they can share rare resources without acquiring the right of ownership for them [2]. These trends are amplified by digitalization, increasingly integrating production technologies, big data analysis and artificial 
intelligence. The "supplier - manufacturer - consumer" chains work on the principles of intensive customization and individualization of production.

The goals of sustainable development gave rise to the concept of a circular economy - a closed-loop economy. Circular business models are based on the principles of reducing dependence on primary resources, abandoning resources ownership in favor of their joint cyclic use, and the development of technologies for multiple resource processing. All this creates new markets for goods and services [3].

As a result, the boundaries of the company, industry markets, vertically integrated structures, and industrial hubs and clusters are blurred. At the same time, globalization is close to the reverse process - localization, and creative ideas and startups are in demand on the market just like standardized processes.

All this predetermines the need for a new object of analysis that is not tied to firms, industries and markets. Against the background of fierce technologies competition, we believe that such an object could be a system of economic agents and institutions, in which the key system-forming factor is technology - a technological system.

\section{Methods}

\subsection{Research platform for technological systems: complexity theory and neo-institutional economic theory.}

When forming a content-related foundation of the technological systems concept, we rely on theoretical and methodological provisions of two approaches: complexity theory and neo-institutionalism theory.

Complexity theory is based on the idea that the economic environment is dynamically changing complex of institutions, agents and technologies, while economic systems do not always tend toward equilibrium and can demonstrate the effects of increasing returns [4]. Economic dynamics in complexity theory is the result of network interactions of complex nonlinear ecosystems [5].

The object of complexity theory analysis is complex adaptive systems (CAS), which are network communities that consist of separate but functionally related agents. These systems are inseparable from the constantly changing external environment formed by the participants in the course of joint development. They are characterized by the ability to selforganization and self-renewal, and adaptation to each other and the environment through feedback signals and emergent behavior [6]. The equilibrium state is probably not typical for such systems, they tend to the state of dynamic stability.

The question "what are the reasons that keep CAS participants together?" becomes central here. The answer is obvious on closer inspection - a technology or a system of interconnected technologies. However, it does not clarify what are the main motives or conditions that trigger the mechanism of self-sustaining functioning (regulations, updating) of the technological system. The need to understand the incentives that keep participants together in a complex adaptive system, as well as the fact that technology development does not occur in isolation, outside the socio-cultural context, require the inclusion of neoinstitutional economic theory in the research methodology.

Considering technology as a system of interspecific resources and institutions (interspecific and complementary combinations have value only within a specific technology), we believe that the inherent stability of institutions keeps participants through the effect of "path-dependence". As J. Child notes, "the prevailing technology is seen as the result of decisions made regarding work plans, resources, and equipment based on a certain assessment of the organization's position relative to the external environment. The existing 
technological configuration (as a combination of equipment, know-how, etc.) may cause some rigidity (inelasticity) in the short term, as well as possible inability to separate, and, therefore, may act as an obstacle to the adoption of new plans" [7].

The high specificity of resources makes the switching costs of participants significant, which forms a system of self-executing institutional agreements. The existence of selfexecuting agreements is the main factor stabilizing complex contract systems $[8,9]$.

\subsection{Content foundation of the term «technologies»}

The formation of the content basis of technological systems is associated with the need for the genesis of ideas about technology as a basic element of the social structure.

The ideas of technology have evolved from a strictly engineering understanding it as $a$ set of methods and techniques for obtaining, working-up or processing raw and other materials, semi-finished products or items during the second industrial revolution to interpreting it as a volume of knowledge used to produce goods and services from economic resourcesin the industrial economy [10]. Deeper division of labor led to the isolation of the technology creation stage. There have appeared organizations whose product is technology, and, accordingly, technology markets, and it itself has acquired commodity properties. In modern post-industrial economy technology is considered as an object of ownership possessing product independence (separability) and severe market conditions [11].

B. Orlikowski considers the technology model as a system of elements: agents creators of technology, users and decision makers; material artifacts that ensure the performance of tasks in the workplace; institutional characteristics of the organization (internal and external) [12].

V.L. Tambovtsev indicates that any technology has an integrating component - a technological rule that determines the sequence and method of using material resources. He interprets technology as" a set of material artifacts (things and/or living beings) used by individuals in accordance with technological rules (algorithms) to transform resources into a certain result (product)"[13].

\section{Results and Discussions}

The structure of the technology can be represented as a core and periphery (other names support network, infrastructure). The core of the technology differs from the periphery by the rigidity of technological rules determined by the laws of engineering, physical and chemical properties of substances. Failure to comply with these rules leads to irregularities in the procedure and failure to obtain a result. O.S. Sukharev calls them formal norms (institutes). In addition to strict technological rules, the periphery may also contain informal rules - people's skills and abilities, customs and traditions of process implementation that are not fixed in technological regulations [14]. Thus, technology as a way of obtaining results appears as a system or algorithm for implementing formal and informal institutions.

A distinctive feature of complex adaptive systems is a high degree of decentralization and interaction of network participants through feedback signals. For this reason, the problem of formalizing and fixing the rules of network coordination arises here. We believe it can be solved by forming common technological standards. They are based on the concept of a technological paradigm - a pattern of interactions between the dominant construction of technology and the cognitive system of a community of practitioners who apply their knowledge and skills to develop the core of technology [15]. On the one hand, the technology reflects the sequence of operations and applied methods and techniques (technological rules), and on the other hand, it determines the choice of necessary equipment, tools, controls, methods of labor organization, and management. Thus, the 
technological paradigm is a set of behavioral practices that require a certain institutional environment [13], which, in our opinion, is formed by a complex adaptive network of participants implementing technologies with similar formal rules.

Thus, we come to the following definition: a technological system is a special coordination mechanism, the boundaries of which are defined by a bunch of interconnected technologies functioning continuously through the implementation of self-executing institutional agreements based on common standards and independent of ownership rights.

The structure of a technological system is the core - the basic technology, and the periphery - a network of complementary technologies. Therefore, we observe a fractal structure of the technological system (rather than a hierarchical one), because each component of its technology is also a core (formal technological rules) and a periphery (formal and informal rules).

Economic agents - carriers of technologies form a multi-level network with complex structured institutional agreements. The core of a technological system can be polycentric, that is, a bundle of technology ownership rights can be distributed among several firms. At the same time, the owners of the main technology can perform the functions of a mediator of the entire technological system - to determine the rules for connecting to the network and coordination within it. But we believe that there are technological systems without a mediator that function on the principles of self-regulation and meet the primary characteristics of open ecosystems.

Taking these parameters into account allows us to classify the types of technological systems as follows (Fig.1).

\begin{tabular}{|c|c|c|}
\hline \multirow{2}{*}{ 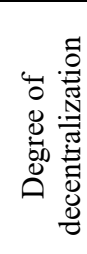 } & $\begin{array}{l}\text { The technology is owned by one firm. } \\
\text { There is no multi-level network mediator. }\end{array}$ & $\begin{array}{l}\text { The technology is owned by several } \\
\text { firms. There is no multi-level network } \\
\text { mediator. }\end{array}$ \\
\hline & $\begin{array}{l}\text { The technology is owned by one firm - a } \\
\text { multi-level network mediator. }\end{array}$ & $\begin{array}{l}\text { The technology is owned by several firms } \\
\text { forming the core (mediator) of a multi- } \\
\text { level network. }\end{array}$ \\
\hline
\end{tabular}

Fig. 1. Classification of technological systems

Thus, the boundaries of technological systems will be determined by the boundaries of institutional agreements between their participants, beyond which switching costs become insignificant, and not by the boundaries of the technologies themselves. Since the periphery of technology includes not only formal technological rules, but also unspoken traditions and uncoded knowledge.

\section{Conclusions}

The ideas of technological determinism, which appeared in the 1920s at the peak of the rapid industrial development and were subsequently criticized for the "reductionist approach", are now taking a new meaning. Technological determinism sees technology as the primary driving force of human evolution. K. Marx, for example, argued that "social relations and cultural practices ultimately revolve around the technological and economic base of society." And T. Veblen was convinced that "the machine changes the anthropomorphic habits of thinking" [16]. Technology is understood as a combination of raw materials, machines and production methods in the works of adherents of technological 
determinism. Criticizing this approach, D. Chandler notes that "in addition to technology, the vector of development of society is determined by political control, class interests, economic pressure, geographical access, education, and general views" [17].

The current interpretation of technology, which includes resources, institutions, and economic agents, expands and constitutes the causal relationships of social evolution. Structuring the economic system in the form of technological systems of various types and complexity will allow us to answer the questions that arise when studying hybrid institutional agreements, namely, their stability and ensuring cooperative (rather than competitive) behavior of participants without losing the advantages of decentralized decision-making and determining effective parameters of state policy for managing the sustainable development of society.

\section{References}

1. S.G. Kirdina-Chandler, Journal of institutional studies, 3 (10) (2018)

2. S.V. Orekhova, F.Ya. Legotin, Bulletin of the Ural State University of Economics, 4 (60) (2015)

3. M.V. Evseeva, Manager, 3 (11) (2020)

4. W. B. Arthur, Complexity and the Economy: a Different Framework for Economic Thought (2013)

5. M. G.Russell, N. V. Smorodinskaya, Technological Forecasting and Social Change, 136 (2018)

6. C. A. Hidalgo, R. Hausmann, The building blocks of economic complexity, 186 (2009)

7. J. Child, Sociology, 6 (1972)

8. E. G. Furubotn, R. Richter, Institutions and economic theory (2005)

9. B.Klein, Journal of Institutional and Theoretical Economics, 141 (1985)

10. V.M. Rozin, Philosophy and Cosmology, 19 (2017)

11. T. M. Gerashchenkova, N. V.Glushak, O.V. Glushak, Smart Innovation, Systems and Technologies, 138 (2020)

12. W. Orlikowski, Organization Science, 3(3) (1992)

13. V. L. Tambovtsev, Journal of New Economy, 2 (20) (2019)

14. O.S. Sukharev, Economic Sciences of Modern Russia, 2 (81) (2018)

15. A.Peine, Research Policy, 3 (37) (2008)

16. B. Bimber, Social Studies of Science, (2) 20 (1990)

17. D. Chandler, Technological or Media Determinism (2000) 